\title{
Effect of Integrated, Person-Centred Palliative Advanced Home and Heart Failure Care on NT-proBNP Levels: A Substudy of the PREFER Study
}

\author{
Fryxell Jenni' ${ }^{1}$, Olofsson Mona ${ }^{2,3}$, Brännström Margareta ${ }^{4}$, Boman Kurt ${ }^{2,3^{*}}$ \\ ${ }^{1}$ Anderstorp Health Care Center, Skellefteå Hospital, Skellefteå, Sweden \\ ${ }^{2}$ Research Unit, Medicine-Geriatric Clinic, Skellefteå Hospital, Skellefteå, Sweden \\ ${ }^{3}$ Department of Public Health and Clinical Medicine, Umea University, Umea, Sweden \\ ${ }^{4}$ Department of Nursing, Umea University, Campus Skellefteå, Skellefteå, Sweden \\ Email: *kurt.boman@regionvasterbotten.se
}

How to cite this paper: Jenni, F., Mona, O., Margareta, B. and Kurt, B. (2021) Effect of Integrated, Person-Centred Palliative Advanced Home and Heart Failure Care on NT-proBNP Levels: A Substudy of the PREFER Study. World Journal of Cardiovascular Diseases, 11, 1-10.

https://doi.org/10.4236/wjcd.2021.111001

Received: October 19, 2020

Accepted: January 10, 2021

Published: January 13, 2021

Copyright $\odot 2021$ by author(s) and Scientific Research Publishing Inc. This work is licensed under the Creative Commons Attribution International License (CC BY 4.0).

http://creativecommons.org/licenses/by/4.0/

\section{(c) (i) Open Access}

\begin{abstract}
Objective: In 2012, we initiated a new person-centred model, integrated Palliative advanced home caRE and heart FailurE caRe (PREFER), to integrate specialised palliative home care with heart failure care. Natriuretic peptide-guided treatment is valuable for younger patients (age $<75$ years), but its usefulness in palliative care is uncertain. We explored whether patients in PREFER reduced mean level of N-terminal pro B-type natriuretic peptide (NT-proBNP) more than the control group. Design: A pre-specified, exploratory substudy, analysed within the prospective, randomised PREFER study, which had an open, non-blinded design. Participants: Patients in palliative care with chronic heart failure, New York Heart Association class III-IV were randomly assigned to an intervention ( $\mathrm{n}=36 ; 26$ males, 10 females, mean age: 81.9 years) or control group ( $\mathrm{n}=36 ; 25$ males, 11 females, mean age: 76.5 years). The intervention group received the PREFER intervention for 6 months. The control group received care as usual at a primary health care centre or heart failure clinic at the hospital. NT-proBNP was measured at the start and end of study. Results: Plasma levels of NT-proBNP differed significantly between groups at baseline. By the end of the study, no significant difference was found between the groups. The mean value for NT-proBNP decreased by $35 \%$ in the PREFER group but was not statistically significant $(\mathrm{P}=$ 0.074); NT-proBNP increased $4 \%$ in the control group. Conclusions: We found no statistically significant reductions of NT-proBNP levels neither between nor within the PREFER and the control group at the end of the study.
\end{abstract}




\section{Keywords}

Chronic Heart Failure, Palliative Care, Integrated Care, NT-proBNP, Elderly

\section{Introduction}

Patients with chronic heart failure (CHF) have symptoms as severe and distressing as those of patients with cancer, but do not have equal access to palliative care [1]. The course of CHF is unpredictable, complicating the choice of a specific point for introducing palliative care into general heart failure management [2]. In addition, patients with CHF often require frequent hospitalizations and readmissions, suggesting insufficient management that may be attributable to the frequency of concomitant chronic diseases [1] [3] [4].

In recent years, several groups have sought to characterise the impact of $\mathrm{CHF}$ on symptom burden, quality of life, morbidity and mortality [1] [5] [6]. Others have examined how to improve and individualize CHF treatment, including evaluation of natriuretic peptide (NP)-guided treatment of heart failure [7] [8] [9] [10] [11]. NP-guided treatment seems to be valuable for younger patients (age $<75$ years) with reduced mortality and morbidity, but study results for older patients (age $\geq 75$ ) are contradictory [8] [9] [10] [12] [13]. The plasma concentration of NP can be used in initial diagnostic testing and elevated NPs help identify those who have a worse prognosis and may require further cardiac investigations and/or treatment. Serial NP measurements may guide drug treatment for patients with CHF [14] [15], but the role of these measurements in palliative care has not been evaluated.

In 2012, a new model became available that integrated specialized palliative home care with heart failure care. The person-centred Palliative advanced home caRE and heart FailurE caRe (PREFER) model reduced readmissions, length of stay, and symptoms and improved quality of life [16]. In addition, patients [17] and relatives [18] experienced increased security compared to traditional care. Person-centred integrated care of patients also is associated with increased evidence-based drug treatment, especially mineral corticoid receptor antagonists [19]. Given these findings, we hypothesised that patients receiving the PREFER model of treatment would have greater reductions of $\mathrm{N}$-terminal pro B-type NP (NT-proBNP) levels than those receiving usual care.

\section{Aim}

Our aim was to explore whether the integrated heart failure and palliative homecare in the PREFER group led to a greater reduction of NT-proBNP levels compared to the usual care group.

\section{Patients and Methods}

From January 2011 to October 2012, a total of 72 patients with CHF, were diag- 
nosed according to the ESC guidelines [3]. Patients in the PREFER study were randomized in an open non-blinded design with envelopes in blocks of 20 to the intervention group $(n=36)$ or to usual care $(n=36)$. The design and results have been described and presented elsewhere [16]. The present study was a pre-specified explorative substudy, analyzed within the prospective randomized PREFER study.

Blood sampling of NTproBNP at baseline and at six months (end of study) took place from fasting patients who had rested for 20 minutes, 3600 rates per minutes. After 5 minutes, the samples were centrifuged for 10 minutes at $4^{\circ} \mathrm{C}$ and then stored frozen at $-70^{\circ} \mathrm{C}$. NT-proBNP was analysed at our local laboratory using a clinically available immunoassay, Roche Elecsys (Roche Diagnostics) [20].

\subsection{Statistical Analysis}

The results are presented as mean \pm standard deviation or number (percent). Baseline and end-of-study values of NT-proBNP were not normally distributed and thereby log-transformed. The difference in NT-proBNP levels between baseline and study end is presented as both a numerical and a categorised difference. Compared to levels at baseline, lower levels of NT-proBNP at the end of the study were defined as "improved" and higher levels as "impaired", respectively.

Differences between the PREFER and control groups were evaluated with $\mathrm{Chi}^{2}$ test for categories or Student $t$-tests for normally distributed or logarithmic data. Within-group analysis was analysed with paired sample t-tests. We used univariate and multivariate logistic regression analyses or linear regression analysis to test associations of independent variable and outcome (difference between baseline and end of study) of NT-proBNP. For multivariate analysis, we adjusted for predetermined variables (age, sex, weight, renal function). $\mathrm{P}<0.05$ was considered to indicate significance. For all statistical analyses, IBM SPSS Statistics 22.0 was used.

\subsection{Ethics}

All study participants gave oral and written informed consent. The study is based on the principles of the Helsinki Declaration. It is approved by the Regional Ethics Examination Board at Umeå University (dnr. 2010-294-31M), and the main PREFER study is registered at http://www.clinicaltrials.gov (reg no. NCT0130481).

\section{Results}

Seventy-two patients in palliative care with CHF, New York Heart Association class III-IV were randomly assigned to an intervention ( $\mathrm{n}=36 ; 26$ males, $10 \mathrm{fe}$ males, mean age: 81.9 years) or control group $(\mathrm{n}=36$; 25 males, 11 females, mean age: 76.5 years). At six months eight patients had died in the PREFER group and four in the control group. At baseline, only mean age differed signifi- 
cantly between the PREFER and control group. Baseline characteristics are shown in Table 1.

Baseline values and differences in NT-proBNP levels between baseline and the end of the study are shown in Table 2. Plasma NT-proBNP levels differed significantly between groups at baseline but not at the end of the study. Of note, the mean value of NT-proBNP decreased from 11,893 to $7764 \mathrm{ng} / \mathrm{L}$ (35\% decrease) in the PREFER group, although this decrease was not statistically significant $(\mathrm{P}=$ 0.074). NT-proBNP increased from 5407 to $5608 \mathrm{ng} / \mathrm{L}$ ( $4 \%$ increase) in the control group (Figure 1).

Table 1. Baseline characteristics.

\begin{tabular}{|c|c|c|c|}
\hline Variable & $\begin{array}{c}\text { PREFEER } \\
\mathrm{n}=36\end{array}$ & $\begin{array}{c}\text { Control } \\
n=36\end{array}$ & $\mathrm{P}$ \\
\hline Age & $81.9 \pm 7.2$ & $76.6 \pm 10.2$ & 0.01 \\
\hline \multicolumn{4}{|l|}{ Gender } \\
\hline Female & $10(27.8)$ & $11(30.6)$ & 0.80 \\
\hline Male & $26(72.2)$ & $25(69.4)$ & 0.80 \\
\hline \multicolumn{4}{|l|}{ Marital status } \\
\hline Single & $14(39.0)$ & $14(39.0)$ & 1.00 \\
\hline Married/Cohabiting & $22(61.0)$ & $22(61.0)$ & 1.00 \\
\hline \multicolumn{4}{|l|}{ Smoking } \\
\hline Never & $13(36.1)$ & $14(38.9)$ & 0.81 \\
\hline Former & $21(58.3)$ & $17(47.2)$ & 0.35 \\
\hline Actual/unknown & $2(5.6)$ & $5(13.8)$ & 0.23 \\
\hline \multicolumn{4}{|l|}{ Alcohol } \\
\hline Never & $15(41.7)$ & $13(36.1)$ & 0.09 \\
\hline Regular use & $16(44.4)$ & $17(47.2)$ & 0.41 \\
\hline Unknown & $5(13.9)$ & $6(16.7)$ & 0.26 \\
\hline History of primary cardiovascular disease for $\mathrm{CHF}$ & $26(77.2)$ & $26(77.2)$ & 1.00 \\
\hline Hypertension & $9(25.0)$ & $9(25.0)$ & 1.00 \\
\hline Ischemic Heart disease & $13(36.1)$ & $13(36.1)$ & 1.00 \\
\hline Valve disease & $1(2.8)$ & $1(2.8)$ & 1.00 \\
\hline Other (e.g., cardiomyopathy) & $3(8.4)$ & $3(8.4)$ & 1.00 \\
\hline Unknown & $10(28.0)$ & $10(28.0)$ & 1.00 \\
\hline \multicolumn{4}{|l|}{ Other illness in health history } \\
\hline History of atrial fibrillation/flutter & $23(63.9)$ & $22(61.1)$ & 0.81 \\
\hline History of pulmonary disorder & $15(41.7)$ & $18(50.0)$ & 0.48 \\
\hline History of stroke & $14(38.9)$ & $12(33.3)$ & 0.56 \\
\hline Renal disorder & $10(27.8)$ & $11(30.6)$ & 0.57 \\
\hline Depression & $6(16.7)$ & $12(33.3)$ & 0.30 \\
\hline Diabetes & $13(19.4)$ & $8(16.6)$ & 0.07 \\
\hline History of malignancy & $6(16.7)$ & $2(5.6)$ & 0.13 \\
\hline New York Heart Association class & & & \\
\hline
\end{tabular}




\section{Continued}

\begin{tabular}{|c|c|c|c|}
\hline III & $28(77.8)$ & $23(63.9)$ & 0.34 \\
\hline IV & $8(22.2)$ & $11(30.6)$ & 0.34 \\
\hline \multicolumn{4}{|l|}{ Blood pressure baseline } \\
\hline Systolic mmHg & $124 \pm 25.8$ & $120 \pm 19.9$ & 0.42 \\
\hline Diastolic mmHg & $70 \pm 12.5$ & $74 \pm 9.7$ & 0.12 \\
\hline \multicolumn{4}{|l|}{ Systolic function, \% ejection fraction } \\
\hline Preserved, $40 \%$ - $49 \%$ & $13(36.1)$ & $12(33.3)$ & 0.80 \\
\hline Reduced, $30 \%$ - 39\% & $16(44.4)$ & $21(58.3)$ & 0.36 \\
\hline Reduced, $<30 \%$ & $7(19.4)$ & $3(8.3)$ & 0.17 \\
\hline Creatinine $>130 \mathrm{mmol} / \mathrm{L}$ & $12(33.3)$ & $12(33.3)$ & 1.00 \\
\hline Glomerular filtration rate $<60 \mathrm{~mL} / \mathrm{min}$ & $25(69.4)$ & $22(61.1)$ & 0.46 \\
\hline Anemia $<120 \mathrm{~g} / \mathrm{L}$ & $19(52.7)$ & $15(41.7)$ & 0.29 \\
\hline \multicolumn{4}{|l|}{ Dyspnea } \\
\hline None & $1(2.8)$ & $2(5.6)$ & 0.56 \\
\hline Mild & $8(22.2)$ & $6(16.6)$ & 0.55 \\
\hline Moderate & $23(63.9)$ & $22(61.1)$ & 0.81 \\
\hline Severe & $4(11.1)$ & $6(16.7)$ & 0.50 \\
\hline \multicolumn{4}{|l|}{ Fatigue } \\
\hline None/missing & $3(8.3)$ & $4(11.1)$ & 0.69 \\
\hline Mild & $10(27.8)$ & $7(19.4)$ & 0.41 \\
\hline Moderate & $16(44.4)$ & $15(41.7)$ & 0.81 \\
\hline Severe & $7(19.4)$ & $10(27.8)$ & 0.41 \\
\hline \multicolumn{4}{|l|}{ Treatment } \\
\hline Renin-angiotensin system blockade & $32(86.1)$ & $33(91.7)$ & 0.69 \\
\hline Beta-blocker & $30(83.3)$ & $31(86.1)$ & 0.74 \\
\hline Mineralocorticoid receptor antagonist & $10(27.8)$ & $13(36.1)$ & 0.45 \\
\hline Loop diuretics & $32(88.9)$ & $30(83.3)$ & 0.50 \\
\hline Digitalis & $8(22.2)$ & $5(13.9)$ & 0.36 \\
\hline Nitrates & $12(33.3)$ & $11(30.6)$ & 0.80 \\
\hline Statins & $12(33.3)$ & $18(50.0)$ & 0.15 \\
\hline Anticoagulants & $17(47.2)$ & $17(47.2)$ & 1.00 \\
\hline Acetylsalicylic acid/platelet inhibitors & $21(58.3)$ & $15(41.7)$ & 0.16 \\
\hline Number of other drug treatments, median & 5 & 6 & 0.73 \\
\hline \multicolumn{4}{|l|}{ Devices, procedures } \\
\hline Cardiac resynchronisation therapy & $3(8.3)$ & $4(10.1)$ & 0.35 \\
\hline Pacemaker & $4(11.1)$ & $5(13.9)$ & 0.72 \\
\hline Valve operations & $4(11.1)$ & $3(8.3)$ & 0.69 \\
\hline $\begin{array}{l}\text { History of coronary artery bypass } \\
\text { graft/percutaneous coronary intervention }\end{array}$ & $17(47.2)$ & $13(36.1)$ & 0.34 \\
\hline
\end{tabular}

The variables are presented as number, (\%) or mean \pm standard deviation. Classification of dyspnea and fatigue were performed according to the Swedish HF registry. 
Table 2. NT-proBNP levels.

\begin{tabular}{lccc}
\hline \multicolumn{1}{c}{ Plasma NT-proBNP levels, ng/L } & PREFER & Control & P \\
\hline \multicolumn{1}{c}{ Baseline, mean \pm SD } & $11,893 \pm 15,416 \mathrm{~N}=36$ & $5407 \pm 5280 \mathrm{~N}=36$ & 0.021 \\
& $7764 \pm 10086$ & $5608 \pm 6398$ & 0.330 \\
End of study, mean \pm SD & $\mathrm{N}=28$ & $\mathrm{~N}=32$ & \\
$\begin{array}{l}\text { Mean } \pm \text { SD of differences (baseline to end } \\
\text { of study) }\end{array}$ & $1332 \pm 7243$ & $-634 \pm 4735$ & 0.210 \\
Logarithmic baseline, mean \pm SD & $3.80 \pm 0.52$ & $3.56 \pm 0.42$ & 0.028 \\
Logarithmic end of study, mean \pm SD & $3.63 \pm 0.48$ & $3.52 \pm 0.47$ & 0.350 \\
$\begin{array}{l}\text { Mean } \pm \text { SD differences (Log baseline vs } \\
\text { log end of study) }\end{array}$ & $0.12 \pm 0.33$ & $0.0053 \pm 0.30$ & 0.180 \\
Categorised difference: & $\mathrm{N}=28$ & $\mathrm{~N}=32$ & \\
\multicolumn{1}{c}{ Improved NT-proBNP } & 20 & 16 & 0.091 \\
\multicolumn{1}{c}{ Impaired NT-proBNP } & 8 & 16 & 0.091 \\
\hline
\end{tabular}

The variables are presented as number or mean \pm standard deviation (SD).

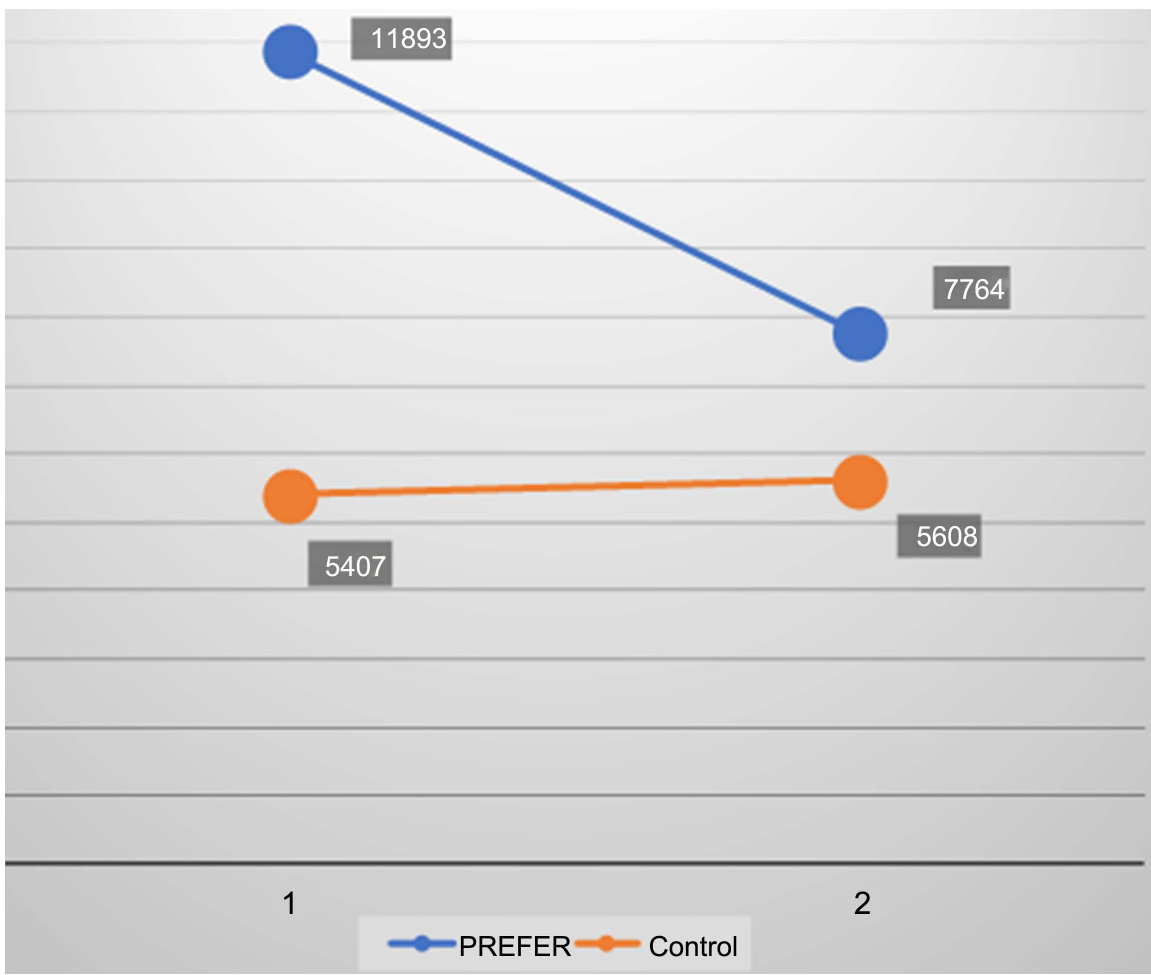

Figure 1. Changes in mean values for NT-proBNP.

Multivariate analyses with adjustments for age, sex, renal function, and weight showed no significant differences between the PREFER and control groups for changes in NT-proBNP (unadjusted, $\mathrm{P}=0.094$; adjusted, $\mathrm{P}=0.057$ ).

\section{Discussion}

The main finding of this exploratory study was that the PREFER and controls 
groups did not differ significantly at the end of the study for mean levels of NT-proBNP. Therefore, the proposed null hypothesis could not be rejected.

Our results are in line with the meta-analysis of De Vecchis et al. [12]. They found an association of NP-guided therapy with both lower mortality and morbidity for people under age 75 years but not over age 75 years. In contrast, the PROTECT study showed that NT-proBNP-guided treatment was associated with decreased cardiovascular event rates for people over age 75 years [10]. They argued that treatment in the older age groups as in previous studies, such as TIME-CHF [8]. Or BATTLESCARRED [9], failed to lower NT-proBNP to clinically relevant, predefined levels, which could explain why an absence of positive results in the older age group. Other studies have shown significant reductions in NT-proBNP levels following medical treatment of CHF [21] [22] [23]. In the current work, we identified a numerical reduction in mean NT-proBNP value, suggesting that NT-proBNP can be lowered in this older age group. The numerical improvement with PREFER may be linked to the significant optimisation of recommended drug treatment as previously reported [19]. The marked reductions of hospitalizations found in the PREFER study [16] suggest that other components of the model, such as the team-based and person-centred care and the continuity may be of equal or of greater importance than improvements of drug treatment. Further and larger clinical studies are needed to further explore the relationship between NT-proBNP and clinical outcomes in palliative care.

\section{Clinical Implications}

The role of NT-proBNP measurements in the care of older patients with severe heart failure and in palliative care is still not clear. Medical treatment plays an important role, but improvements in drug treatment for elderly people with CHF require careful monitoring and consideration because the drugs have side effects that can lead to severe complications such as confusion, kidney impairment, or fall trauma with fractures. Fully optimising drug treatment requires meticulous monitoring and measuring NT-proBNP levels may become a useful tool, but this must be further examined.

\section{Limitations}

The study has several limitations. The PREFER substudy was a one-centre exploratory study with limited number of patients involving no power calculations for changes in NT-proBNP. For this reason, a type 2 error cannot be excluded.

Patients in the PREFER group were significantly older than those in the control group, but adjustments were made for this difference in the analyses. The intervention in the PREFER trial did not use NT-proBNP to monitor and adjust drug treatment to a certain level.

\section{Conclusions}

We found no significant reductions in NT-proBNP levels between or within the 
PREFER and control groups for six months treatment.

\section{Conflicts of Interest}

The authors declare no conflicts of interest regarding the publication of this paper.

\section{References}

[1] Brännström, M., Hägglund, L., Furst, C.J. and Boman, K. (2012) Unequal Care for Dying Patients in Sweden: A Comparative Registry Study of Deaths from Heart Disease and Cancer. European Journal of Cardiovascular Nursing, 11, 454-459. https://doi.org/10.1016/j.ejcnurse.2011.06.007

[2] Läkemedelsverket, S.M.P.A. (2006) Diagnos och behandling av kroniskt hjärtsvikt/ Diagnosis and Treatment of Chronic Heart Failure. Läkemedelsverket/Medical Products Agency.

[3] Ponikowski, P., Voors, A.A., Anker, S.D., et al. (2016) ESC Guidelines for the Diagnosis and Treatment of Acute and Chronic Heart Failure: The Task Force for the Diagnosis and Treatment of Acute and Chronic Heart Failure of the European Society of Cardiology (ESC) Developed with the Special Contribution of the Heart Failure Association (HFA) of the ESC. European Heart Journal, 37, 2129-2200. https://doi.org/10.1093/eurheartj/ehw128

[4] Collaboration R.C.I.S.R.C.C.I. (2016) Nationellt vårdprogram, Palliativ vård i livets slutskede/National Care Program, Palliative Care.

[5] Hobbs, F.D., Kenkre, J.E., Roalfe, R.C., Davis, R.C., Hare, R. and Davies, M.K. (2002) Impact of Heart Failure and Left Ventricular Systolic Dysfunction on Quality of Life: A Cross-Sectional Study Comparing Common Chronic Cardiac and Medical Disorders and a Representative Adult Population. European Heart Journal, 23, 1867-1876. https://doi.org/10.1053/euhj.2002.3255

[6] Chan, H.Y., Yu, D.S., Leung, D.Y. Chan, A.W. and Hui, E. (2016) Quality of Life and Palliative Care Needs of Elderly Patients with Advanced Heart Failure. Journal of Geriatric Cardiology, 13, 420-424.

[7] Ng, A.Y.M. and Wong, F.K.Y. (2017) Effects of a Home-Based Palliative Heart Failure Program on Quality of Life, Symptom Burden, Satisfaction and Caregiver Burden: A Randomized Controlled Trial. Journal of Pain and Symptom Management, $55,1-11$.

[8] Pfisterer, M., Buser, P., Rickli, H., et al. (2009) BNP-Guided vs Symptom-Guided Heart Failure Therapy: The Trial of Intensified vs Standard Medical Therapy in Elderly Patients with Congestive Heart Failure (TIME-CHF) Randomized Trial. $J A M A, 301,383-392$. https://doi.org/10.1001/jama.2009.2

[9] Lainchbury, J.G., Througton, R.W., Strangman, K.M., et al. (2009) N-Terminal Pro-B-Type Natriuretic Peptide-Guided Treatment for Chronic Heart Failure: Results from the BATTLESCARRED (NT-proBNP-Assisted Treatment to Lessen Serial Cardiac Readmissions and Death) Trial. Journal of the American College of Cardiology, 55, 53-60. https://doi.org/10.1016/j.jacc.2009.02.095

[10] Gaggin, H.K., Mohammed, A.A., Bhardwaj, A., et al. (2012) Heart Failure Outcomes and Benefits of NT-proBNP-Guided Management in the Elderly: Results from the Prospective, Randomized ProBNP Outpatient Tailored Chronic Heart Failure Therapy (PROTECT) Study. Journal of Cardiac Failure, 18, 626-634. https://doi.org/10.1016/j.cardfail.2012.05.005 
[11] Karlström, P., Johansson, P., Dahlström, U., et al. (2016) Can BNP-Guided Therapy Improve Health-Related Quality of Life, and Do Responders to BNP-Guided Heart Failure Treatment Have Improved Health-Related Quality of Life? Results from the UPSTEP Study. BMC Cardiovascular Disorders, 16, 39. https://doi.org/10.1186/s12872-016-0221-7

[12] De Vecchis, R., Esposito, C., Di Biase, G., Ariano, C., Giasi, A. and Cioppa, C. (2014) B-Type Natriuretic Peptide-Guided versus Symptom-Guided Therapy in Outpatients with Chronic Heart Failure: A Systematic Review with Meta-Analysis. Journal of Cardiovascular Medicine (Hagerstown), 15, 122-134. https://doi.org/10.2459/JCM.0b013e328364bde1

[13] Bhardwaj, A., Rehman, S.U., Mohammed, A.A., et al. (2012) Quality of Life and Chronic Heart Failure Therapy Guided by Natriuretic Peptides: Results from the ProBNP Outpatient Tailored Chronic Heart Failure Therapy (PROTECT) Study. American Heart Journal, 164, 793-799. https://doi.org/10.1016/j.ahj.2012.08.015

[14] Maisel, A., Mueller, C., Adams Jr., K., et al. (2008) State of the Art: Using Natriuretic Peptide Levels in Clinical Practice. European Journal of Heart Failure, 10, 824-839. https://doi.org/10.1016/j.ejheart.2008.07.014

[15] Läkemedelsverket, S.M.P.A. (2006) Hjärtsvikt och asymtomatisk vänsterkammardysfunktion-Läkemedelsverket/Heart Failure and Asymptomatic Left Vetricular Dysfunction. Läkemedelsverket/Medical Products Agency.

[16] Brännström, M. and Boman, K. (2014) Effects of Person-Centred and Integrated Chronic Heart Failure and Palliative Home Care. PREFER: A Randomized Controlled Study. European Journal of Heart Failure, 16, 1142-1151. https://doi.org/10.1002/ejhf.151

[17] Talabani, N., Hellström-Ängerud, K., Boman, K. and Brännström, M. (2020) Patients' Experiences of Person-Centred Integrated Heart Failure Care and Palliative Care at Home: An Interview Study. BMJ Supportive \& Palliative Care, 10, e9. https://doi.org/10.1136/bmjspcare-2016-001226

[18] Alvariza, A., Arestedt, K., Boman, K. and Brännström, M. (2018) Family Members' Experiences of Integrated Palliative Advanced Home and Heart Failure Care: A Qualitative Study of the PREFER Intervention. Supportive and Palliative Care, 16, 278-285. https://doi.org/10.1017/S1478951517000256

[19] Markgren, R., Brännström, M., Lundgren, C., et al. (2019) Impacts of Person-Centred Integrated Chronic Heart Failure and Palliative Home Care on Pharmacological Heart Failure Treatment: A Sub-Study of a Randomised Trial. BMJ Supportive \& Palliative Care, 9, e10. https://doi.org/10.1136/bmjspcare-2015-000894

[20] Corporations, R.D. (2002) Summary K022516-Elecsys ProBNP NOV 192002 Introduction 2002.

[21] Fung, J.W.H., Yu, C.M., Yip, G., et al. (2003) Effect of Beta Blockade (Carvedilol or Metoprolol) on Activation of the Renin-Angiotensin-Aldosterone System and Natriuretic Peptides in Chronic Heart Failure. The American Journal of Cardiology, 92, 406-410. https://doi.org/10.1016/S0002-9149(03)00658-1

[22] Tsutamoto, T., Wada, A., Maeda, K., et al. (2001) Effect of Spironolactone on Plasma Brain Natriuretic Peptide and Left Ventricular Remodeling in Patients with Congestive Heart Failure. Journal of the American College of Cardiology, 37, 1228-1233. https://doi.org/10.1016/S0735-1097(01)01116-0

[23] Yoshimura, M., Yasue, H., Tanaka, H., et al. (1994) Responses of Plasma Concen- 
trations of A Type Natriuretic Peptide and B Type Natriuretic Peptide to Alacepril, an Angiotensin-Converting Enzyme Inhibitor, in Patients with Congestive Heart Failure. British Heart Journal, 72, 528-533. https://doi.org/10.1136/hrt.72.6.528 